\title{
Growth, Crystal Structure and Characterization of a New Single Crystal: Lithium Sodium Acid Phthalate (LiNaP), for Third Order Nonlinear Optical Applications
}

\author{
B. Sivakumar ${ }^{1}$, S. Gokul Raj ${ }^{2 *}$, G. Ramesh Kumar ${ }^{3}$, R. Mohan ${ }^{1}$ \\ ${ }^{1}$ Department of Physics, Presidency College (Autonomous), Chennai, India; ${ }^{2}$ Department of Physics, VelTech Dr. RR \& Dr. SR \\ Technical University, Chennai, India; ${ }^{3}$ Department of Physics, University College of Engineering Arni, Anna University Chennai, \\ Arni, India. \\ Email: "gokulrajs@yahoo.com,gokulrajs@hotmail.com
}

Received May $30^{\text {th }}, 2012$; revised July $3^{\text {rd }}, 2012$; accepted August $1^{\text {st }}, 2012$

\begin{abstract}
A new alkali metallo-organic single crystal of Lithium Sodium Acid Phthlate (LiNaP) complex has been synthesized from aqueous solution in the equimolar ratio 3:1:2. Transparent and bulk single crystals of dimension $9 \times 4 \times 2 \mathrm{~mm}^{3}$ have been grown from the conventional slow-cooling technique. The crystal structure of the compound has been solved from single crystal X-ray diffraction. The compound $2\left[\mathrm{C}_{8} \mathrm{H}_{4} \mathrm{O}_{3}\right]^{4} \mathrm{Li}^{3+} \mathrm{Na}^{+}$crystallizes in triclinic system with a space group of Pī having cell dimensions $\mathrm{a}=7.5451(2) \AA ; \mathrm{b}=9.8422(3) \AA ; \mathrm{c}=25.2209(7) \AA ; \alpha=80.299(2) ; \beta=89.204(2) ; \gamma$ $=82.7770(10)$. FTIR measurement was carried out for LiNaP to study the vibrational structure of the compound. The various functional groups present in the molecule and the role of H-bonds in stabilizing the crystal structure of the compound have been explained. Optical absorption properties were studied for the grown crystal using UV-Vis-NIR spectrum. Thermal measurements were carried out for LiNaP to determine the thermal strength as well as to ascertain the hydrated nature of the crystal. Third order nonliner optical studies have also studied by Z-scan techniques. Nonlinear absorption and nonlinear refractive index were found out and the third order bulk susceptibility of compound was also estimated. The results of all studies have been discussed in detail.
\end{abstract}

Keywords: Single Crystal X-Ray Diffraction; FTIR Analysis; UV-VIS-NIR Spectroscopy; Thermal Analysis; Nonlinear Optical Materials; Third-Order Nonlinearity; Z-Scan

\section{Introduction}

Crystalline Phthalic acid complexes have been subjected to extensive investigations by several researchers so as to study about their linear and nonlinear optical properties. By analogy, Lithium Sodium Acid Phthlate (LiNaP), a probable third harmonic generator has been chosen for the present study because of its favorable optical properties. In general, Phthalate complexes are being widely investigated for their promising electronic and optoelectronic applications [1-11]. The crystallographic data for many phthalic acid complexes exists in the literature are the salts of Potassium Acid Phthalate (KAP), Sodium Acid Phthalate (NaAP), Lithium Acid Phthalate (LiAP) [12-14]. All of these compounds are stabilized by extensive networks of hydrogen bonds. The influence of strong and weak hydrogen bonds on the nonlinear behaviour of the crystals have already been studied earlier

\footnotetext{
${ }^{*}$ Corresponding author.
}

[15]. These molecular crystals are characterized by the presence of bonds of different types viz., covalent (intramolecular), ionic (cation-anion), van der Waals and as well as intermolecular hydrogen bonds $\mathrm{O}-\mathrm{H} \mathrm{O}$ (H bonds). The H-bonds in these crystals are very short $(-2.5 \AA)$ and therefore are classified as strong H-bonds which are characterized by the possible Fermi-resonance interactions of stretching vibrations of $v(\mathrm{O}-\mathrm{H})$ with sum combinations of bending in-plane $\beta(\mathrm{O}-\mathrm{H})$ and out-of-plane $\gamma$ $(\mathrm{O}-\mathrm{H})$ vibrations owing to intramolecular anharmonicity. Phthalate samples of sodium and potassium are promising third-order NLO materials for applications in optical devices. [16-18].

Hence, a new phthalate based alkali metal complexcrystals of Lithium Sodium Acid Phthalate $2\left[\mathrm{C}_{8} \mathrm{H}_{4} \mathrm{O}_{3}\right]^{4-}$ $\mathrm{Li}^{3+} \mathrm{Na}^{+}(\mathrm{LiNaP})$ has been grown by the slow evaporation of an aqueous solution at room temperature. The molecular units contain delocalized $\pi$-electrons and additional electron donor as well as acceptor groups. The 
compound crystallizes in the triclinic system with a Centrosymmetric space group Pī.

\section{Experimental Procedure}

\subsection{Crystal Growth}

Salts of Lithium hydroxide, Sodium hydroxide and Phthalic acid were taken in the molar ratio 3:1:2 respectively in double distilled de-ionized water. The solution was strongly stirred continuously for 24 hours and subsequently heated for a homogenous mixing. The scheme of reaction in Figure 1 shows the synthesis of Lithium Sodium Acid Phthalate (LiNaP) for which the solution was allowed to cool at room temperature. Platelet and colourless crystals of LiNaP were collected from the mother solution. Good quality LiNaP crystals have been prepared by successive recrystallization and by slow evaporation of the aqueous solution. Bulk \& optically quality crystals having dimensions $9 \times 4 \times 2 \mathrm{~mm}^{3}$ were also grown by the convention slow cooling technique with a typical growth period of 30 days and it is shown in the Figure 2.

\subsection{Characterization Studies}

The grown crystal of Lithium Sodium Acid Phthalate (LiNaP) was subjected to single crystal X-ray diffraction analysis for structural elucidation. A well grinded powder of LiNaP was used for Fourier transform infrared spectroscopy (FTIR), UV-Vis-NIR analyses and for the thermal measurements. Third order nonlinear optical measurements of NaAP crystal has also been studied using

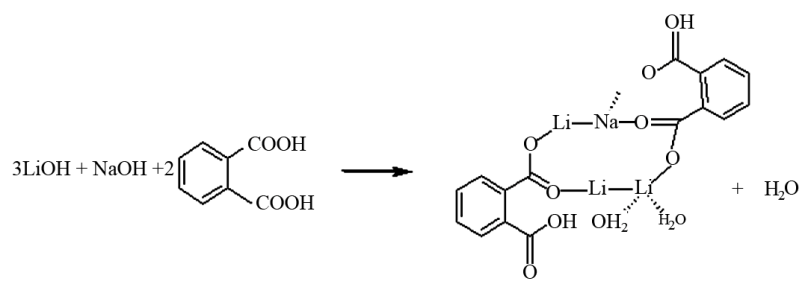

Figure 1. Scheme for the synthesis of LiNaP salt.

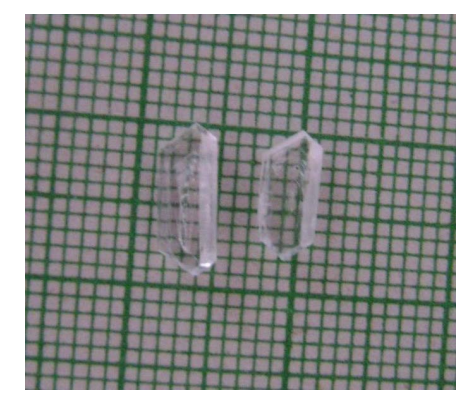

Figure 2. LiNaP single crystals grown from slow evaporation. a simple and versatile Z-scan technique using $\mathrm{He}-\mathrm{Ne}$ laser of wavelength $632.8 \mathrm{~nm}$.

\section{Results and Discussion}

\subsection{Single Crystal X-Ray Diffraction}

The unit cell dimensions and X-ray intensity data of Li$\mathrm{NaP}$ was obtained on a Enraf Nonius CAD 4 Bruker Kappa APEX II single crystal X-ray diffractometer equipped with $\mathrm{MoK} \alpha$ radiation $(\lambda=0.71073 \AA) . \omega / 2 \theta$ scan mode was employed for data collection [19]. The dimension of the crystal used for the measurements was $0.30 \times 0.20 \times 0.20 \mathrm{~mm}^{3}$. A total of 34,587 reflections were measured, out of which 6432 were found unique and its limiting indices were $-8<=\mathrm{h}<=8,-11<=\mathrm{k}<$ $=11$, and $-29<=1<=29$. The maximum and minimum transmission factors were 0.97 and 0.92 . The crystal structure was solved by direct method using SIR92 (WINGX) [20] and refined by a full matrix least-square method using SHELXL97 [21]. The Li, Na atoms were located in different Fourier maps and refined with isotropic thermal parameters. Non-hydrogen atoms were refined with anisotropic displacement parameters. Bond distances of the hydrogen atoms are constrained around the Fourier peak at which they appeared. The other hydrogen atoms were fixed at meaningful positions and were given riding mode refinement. The refinement is continued until max shift/esd. was zero [22]. The final refinement $\mathrm{R}$ factor was 0.0492 .

\subsection{Crystal Structure Data}

The crystal structural refinement details are provided in Table 1. The ORTEP representation of the molecule with 50\% probability is shown in Figure 3.

The crystal structure results confirm that the LiNaP molecule was in Centrosymmetric form. The ring structured phthalic acid molecule is bonded to $\mathrm{Li}^{3+} \& \mathrm{Na}^{+}$ions. The unit cell packing of the crystal shows that there is a three-dimensional network of $\mathrm{O} \cdots \cdot \mathrm{H}--\mathrm{O}$ hydrogen bonds. The alkali ions are linked to each other by $\mathrm{H}^{\cdots \cdots} \mathrm{O}$

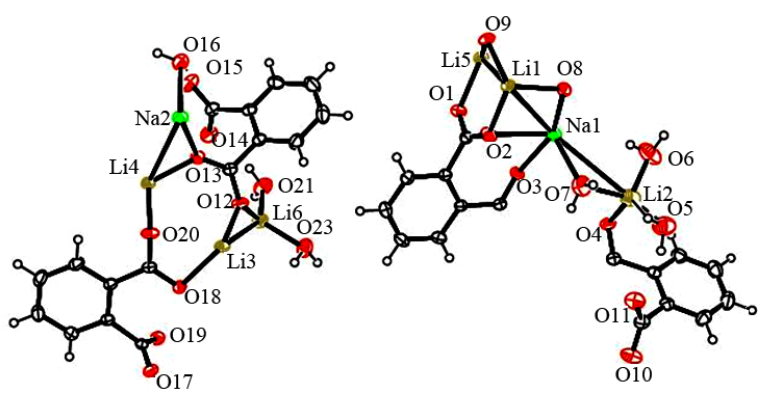

Figure 3. A view of the molecular complex of the LiNaP. 
Table 1. Crystal data and structure refinement for LiNaP.

\begin{tabular}{ll}
\hline \multicolumn{1}{c}{ Compound Details } & \multicolumn{1}{c}{ Experiemental Results } \\
\hline Identification code & $\mathrm{LiNaP}$ \\
Empirical formula & $\mathrm{C}_{16} \mathrm{H}_{14} \mathrm{Li}_{3} \mathrm{NaO}_{11}$ \\
Formula weight & 426.08 \\
Temperature & $293(2) \mathrm{K}$ \\
Wavelength & $0.71073 \AA$ \\
Crystal system \& space & Triclinic, $\mathrm{P} \overline{1}$ \\
group & \\
& $a=7.5451(2) \AA ; \alpha=80.299(2)^{\circ}$. \\
Unit cell dimensions & $b=9.8422(3) \AA ; \beta=89.204(2)^{\circ}$. \\
& $c=25.2209(7) \AA ; \gamma=82.7770(10)^{\circ}$. \\
Volume & $1831.43(9) \AA^{3}$ \\
Z, Calculated density & $4,1.545 \mathrm{Mg} / \mathrm{m}^{3}$ \\
\hline
\end{tabular}

hydrogen bonds through the carboxylic oxygen. The protonation of $\mathrm{Li}$ and $\mathrm{Na}$ ion with the ring hydrogen atom has been confirmed by the meaning-full bond lengths.

The crystal structure is composed of potassium, sodium cations and hydrogen phthalate molecules of crystallization. The angles between the plane through the two phenyl rings of the COO-group and its unionized $\mathrm{COOH}$ group are $\mathrm{O}(18)-\mathrm{C}(31)-\mathrm{O}(20)$ 122.11(17); $\mathrm{O}(19)-\mathrm{C}(32)$ $-\mathrm{O}(17)$ 124.96(17); and $\mathrm{O}(15)-\mathrm{C}(24)-\mathrm{O}(14)$ 125.64(19) and $\mathrm{O}(13)-\mathrm{C}(23)-\mathrm{O}(12)$ 125.06(18). Each carboxylate is hydrogen bonded to a carboxylic group of the neighbouring anion and a hydrogen molecule. The molecules lie on a centrosymmetric plane. The bond lengths of the planes $\mathrm{Li}(3)-\mathrm{Li}(6) ; \quad \operatorname{Li}(3)-\mathrm{Li}(4)$ and $\operatorname{Li}(4)-\mathrm{Na}(2)$ are 3.274(5), 3.442(4) and 3.070(3) § respectively which confirm the alkali metal ions are linear to the intermolecular network. The Lithium atom is connected to the ionized part of the ionic carboxylic group of phthalate molecule with a bond length of 1.957(3) and the same configuration appears for another phthalic acid molecule with a bond length of 1.927(4) $\AA$. The ionized Carboxylic group connected in the same network by the lithium atoms of $\mathrm{O}(18)-\mathrm{Li}(3)$ and $\mathrm{O}(12)-\mathrm{Li}(3)$ possessing the bond lengths of 2.096(3) and 1.963(3) $\AA$ respectively. The variation of bonds lengths of Lithium cations with the oxgen anions in the molecular pack may be due to the difference in the thermal parameters of the molecule. Both sodium and lithium cation are connected to the same carboxylic COO-groups. The Sodium cations forms a ring structured network with $\mathrm{Li}(4)-\mathrm{Na}(2), \mathrm{O}(13)-\mathrm{Na}(2)$ and $\mathrm{O}(13)-\mathrm{Li}(4)$ having bond lengths of 3.070(3), $2.2720(15)$ and $1.927(4) \AA$ respectively where as a triangular structured network was formed by the lithium cation of $\mathrm{O}(12)-\mathrm{Li}(6), \mathrm{O}(12)-\mathrm{Li}(3)$ and $\mathrm{Li}(3)-\mathrm{Li}(6)$ with bond lengths 1.962(4), 1.963(3) and 3.274(5) Å respectively. This may be a one of the predominant factor for the lowering of symmetry of the phthalic acid molecule on the incorporation of the alkali metals of $\mathrm{Li}$ and $\mathrm{Na}$ into the crystal lattice of phthalic acid.

\subsection{Morphology of LiNaP}

The morphology of the Lithium Sodium Acid Phthalate crystals is made up of various planes viz., $\left(\begin{array}{llll}0 & 0 & 1\end{array}\right)\left(\begin{array}{lll}1 & 0 & 0\end{array}\right)$ $\left(\begin{array}{lll}0 & -1 & 0\end{array}\right)\left(\begin{array}{lll}1 & 1 & 0\end{array}\right)\left(\begin{array}{lll}-2 & 1 & 1\end{array}\right)$ and $\left(\begin{array}{lll}0 & -2 & 3\end{array}\right)$ of which $\left(\begin{array}{lll}0 & 0 & 1\end{array}\right)$ is a prominent one and it is shown in Figure 4. The crystal possess a platelet morphology and $\left(\begin{array}{lll}0 & 0 & 1\end{array}\right)$ was found to be larger to other faces with a length to thickness ratio of 10:1 by taking bc-plane as the reference one. The growth habits of LiNaP are along the polar axis and the narrow faces developed at the edges of $\left(\begin{array}{lll}001\end{array}\right),\left(\begin{array}{lll}1 & 0 & 0\end{array}\right)$ and $\left(\begin{array}{lll}-2 & 1 & 1\end{array}\right)$ are almost the same in the very initial stage of crystals grown as seeds in the aqueous solution. Further, it also shows that the prominent and the wider plane $\left(\begin{array}{lll}0 & 0 & 1\end{array}\right)$ is optically transparent and is quite suitable for optical device applications. Since, molecule crystallizes in centrosymmetric space group and may be much useful for the third order non linear optical applications in the UVVisible region.

\subsection{FTIR Spectroscopy}

The Fourier Transform Infrared (FTIR) Spectrum at room temperature in the frequency range $400-4000$ $\mathrm{cm}^{-1}$ recorded with PERKIN ELMER FTIR spectrometer by $\mathrm{KBr}$ pellet method is shown in Figure 5. From the $\mathrm{X}$-ray data, in the previous discussion, it is perceived that only four hydrogen bonds are possible in the molecular species of LiNaP. A broad shoulder at $3415 \mathrm{~cm}^{-1}$ may be due to $\mathrm{OH}$ stretch-g vibrations of the water molecule. The asymmetric and symmetric stretching vibrations of

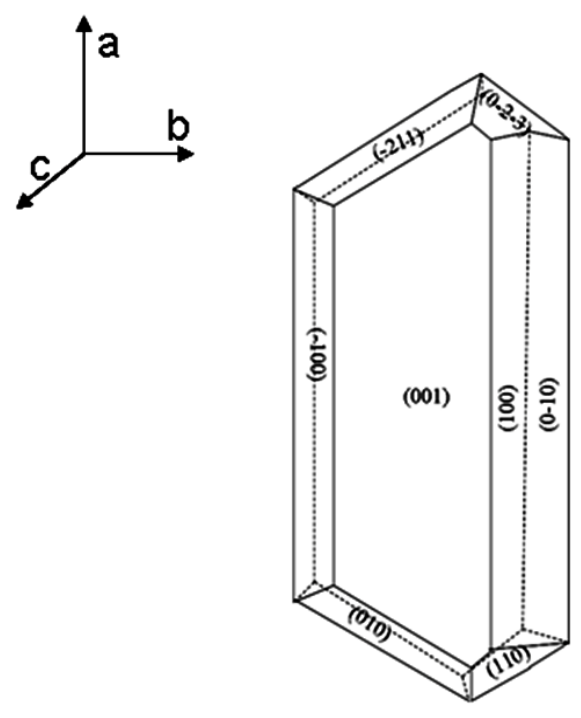

Figure 4. Morphology of LiNaP crystal. 
the ionized carboxyte group are observed at $1581 \mathrm{~cm}^{-1}$. A broad envelope could be found around $\approx 1741 \mathrm{~cm}^{-1}$ may be due to the overtonic vibrations of $\mathrm{H}_{2} \mathrm{O}$. The aromatic ring vibraons are indicated through a peak at 1626 $\mathrm{cm}^{-1}$. The C-C-O stretching vibrations are indicated by the peak at $1117 \mathrm{~cm}^{-1}$.

The $=\mathrm{C}-\mathrm{O}$ out of plane bending and $\mathrm{OH}$ vibrations are indicated by a peak at $878 \mathrm{~cm}^{-1}$. The alkali metal ion vibration is indicated at $538 \mathrm{~cm}^{-1}$. The other vibrations for the phthalic acid group and that for sodium \& lithium along with phthalate molecules are assigned in Table 2, which agree well with the reported values for other phthalate groups [10]. From the ORTEP representation, it is seen that the crystal contains three water molecules.

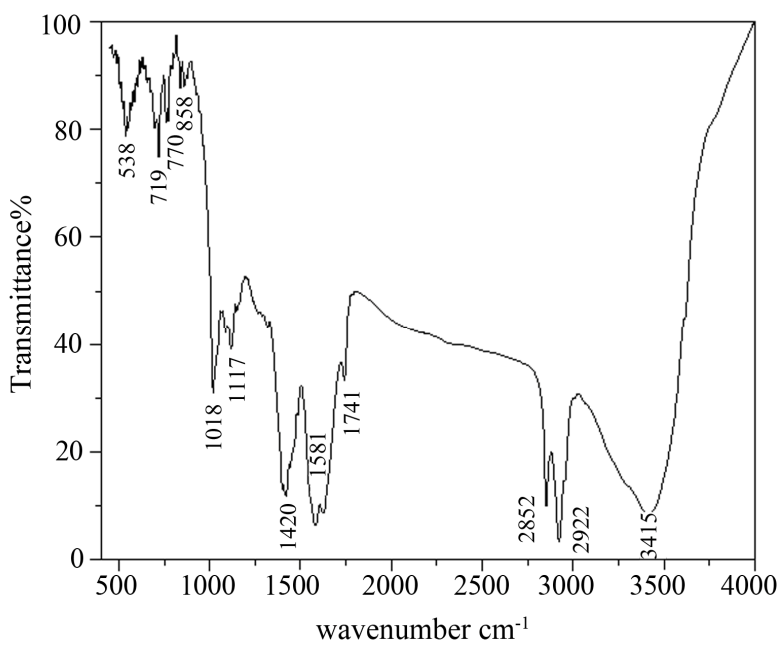

Figure 5. FTIR spectrum of LiNaP single crystal.

Table 2. FTIR assignments of LiNaP.

\begin{tabular}{cc}
\hline Wavenumber $\left(\mathbf{c m}^{-1}\right)$ & Assignments \\
\hline 3415 & OH-stretching \\
2922 & OH stretching intermolecule \\
2852 & C-H stretching \\
1741 & C=O Aromatic Ring + OH over tone \\
1581 & C=O stretching (carboxylate group) \\
1626 & Ring structure \\
1420 & OH bending \\
1117 & C-C-O stretching \\
1018 & C-O stretching (COOH Group) \\
858 & $=$ C-H out of plane bending \\
770 & OH deformation out of plane \\
719 & C=C out of plane deformation \\
538 & Alkali metal ions \\
\hline
\end{tabular}

The O-H...O hydrogen bonds range from $1.847-2.751 \AA$. Since, there are only four hydrogen bonds in the LiNaP crystal, the absorption band at $2922 \mathrm{~cm}^{-1}$ in FTIR spectrum could be assigned to the set of all O-H...O type of Vibrations.

\subsection{UV-Vis-NIR Studies}

The transmittance spectrum of the crystal has been recorded using a Varian Cary 5E UV-Vis-NIR spectrophotometer in the wavelength range $200-1200 \mathrm{~nm}$ is shown in the Figure 6. The lower UV cut-off found to occur at $200 \mathrm{~nm}$. Beyond the " $\lambda$ " maximum, the absorption starts decreasing and the material shows good transparency $(85 \%$ - 90\%) from $300 \mathrm{~nm}$ onwards and it extends upto the maximum value of wavelength studied. The wide transparency window of the title crystal would be much viable for the third harmonic generation for all kinds of laser sources available in the UV-Vis-NIR regime.

\subsection{Thermal Analysis}

Thermal analysis of the title crystal was studied using a NETZSCH STA 409C simultaneous TGA/DTA analyzer and is shown in the Figure 7. In the TGA curve, the weight loss in the temperature range $123^{\circ} \mathrm{C}-130^{\circ} \mathrm{C}$ shows the release of lattice water molecules from the crystal and similar observation was also reciprocated in DTA. An endothermic peak appeared at $292^{\circ} \mathrm{C}$ indicates the partial decomposition of the LiNaP crystals. An exothermic peak at $529^{\circ} \mathrm{C}$ shows the complete decomposition of LiNaP crystal with a carbon residue of $4 \%$.

\subsection{Z-Scan Technique}

The Z-scan technique is a simple, but very accurate me thod to determine both nonlinear index of refraction " $\mathrm{n}_{2}$ "

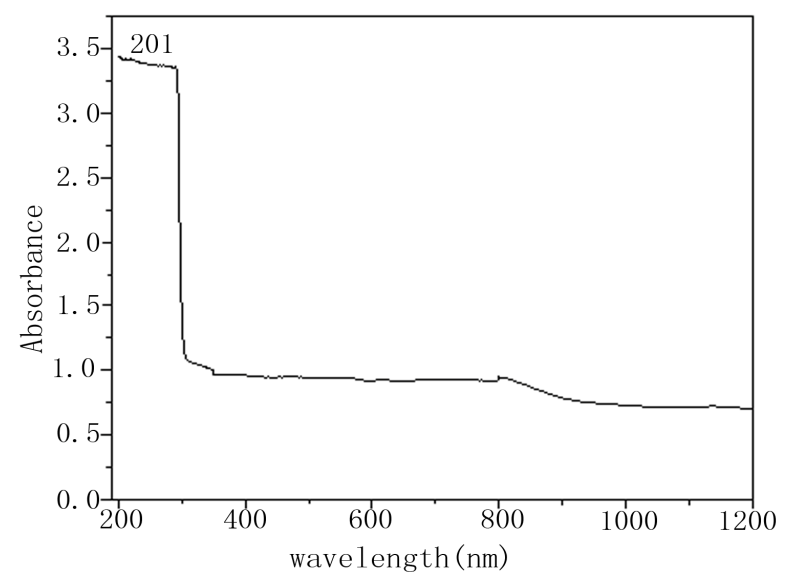

Figure 6. UV-VIS-NIR spectrum of LiNaP single crystal. 


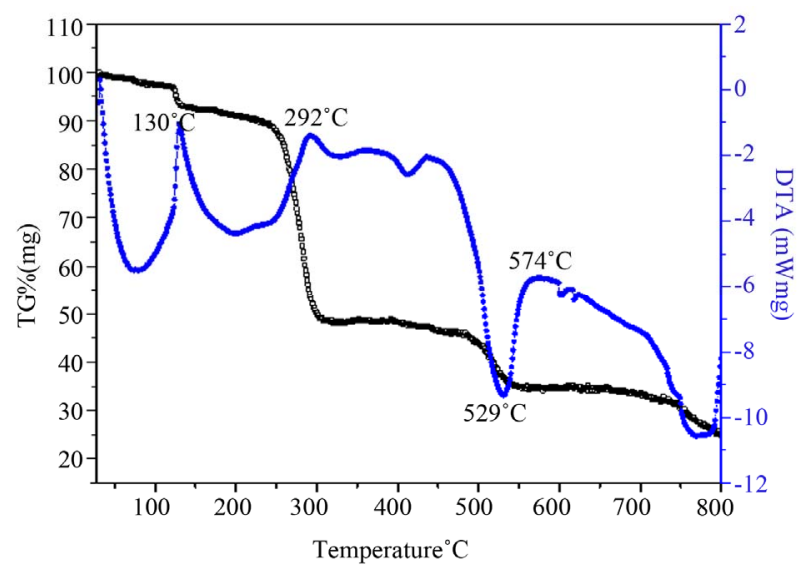

Figure 7. TG and DTA curves of LiNaP single crystal.

and nonlinear absorption coefficient " $\beta$ " and hence to fine the third order susceptibility $\left(\chi_{3}\right)$ which is complex in nature. Nonlinear index of refraction $\left(\mathrm{n}_{2}\right)$ is proportional to the real part of the $\chi_{3} \operatorname{Re}[\omega(3)]$ and the non-linear absorption coefficient is proportional to $\operatorname{Im}[\omega(3)]$ [23]. We used the Z-scan technique [24] to investigate the NLO properties of the LiNaP samples. The Z-scan experiments were performed using a $632.8 \mathrm{~nm} \mathrm{He}-\mathrm{Ne}$ laser beam. The laser beam was focused with a lens of focal length $\mathrm{f}=20 \mathrm{~cm}$ lens and the beam waist radius $\left(\omega_{0}\right)$ was measured to be $3.847 \times 10^{-5} \mathrm{~m}$ and the corresponding Rayleigh length is $7.3 \mathrm{~mm}$. The thickness of a LiNaP single crystal is $0.53 \mathrm{~mm}$, which is far less than the Rayleigh length of the laser beam. The estimation of nonlinear refractive index $\left(\mathrm{n}_{2}\right)$ of the crystal was based on thick sample approximation $\left(\mathrm{R}_{\mathrm{L}}\right)$ and calculated using the standard relations given below (1) [25-27].

$$
\Delta \mathrm{T}_{\mathrm{p}-\mathrm{v}}=0.406(1-\mathrm{S})^{0.25}\left|\Delta \varnothing_{0}\right|
$$

where $\mathrm{S}=1-\exp \left(-r_{a}^{2} / \omega_{a}^{2}\right)$ is the aperture linear transmittance (0.01), $\left|\Delta \emptyset_{0}\right|$ is the on-axis phase shift. The on-axis phase shift is related to the third-order nonlinear refractive index by (2);

$$
\left|\Delta \emptyset_{0}\right| /=\mathrm{kn}_{2} \mathrm{~L}_{\text {eff }} \mathrm{I}_{0}
$$

where $\mathrm{k}=2 \pi / \lambda, \mathrm{L}_{\text {eff }}=[1-\exp (-\alpha \mathrm{L})] / \alpha$ is the effective thickness of the sample, $\alpha$ is the linear absorption coefficient, $\mathrm{L}$ is the thickness of the sample, $\mathrm{I}_{0}$ is the on-axis irradiance at focus and $\mathrm{n}_{2}$ is the third-order nonlinear refractive index.

The results obtained from a typical closed aperture $\mathrm{Z}$-scan study for the grown LiNaP are presented in Figure 8 and the inset figure represents the results of an open aperture technique. From the inset fig., it is inferred that the absorption coefficient nearly reaches saturation

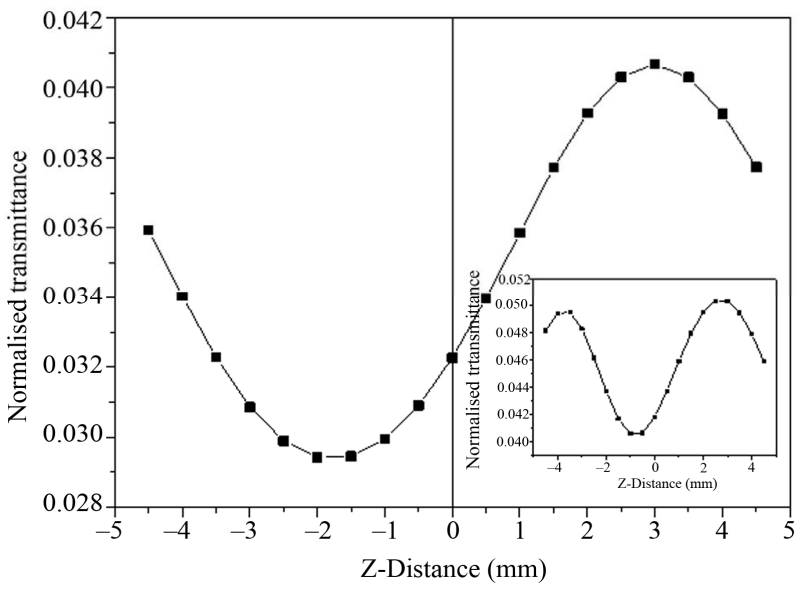

Figure 8. Closed and open aperture Z-scan signatures of LiNaP single crystal.

at the minimum position of $\mathrm{Z}$, but absorption saturation in the sample enhances the peak and decreases the valley in the closed aperture $Z$-scan curve and results in distortions in the symmetry of the $\mathrm{Z}$-scan curve about $\mathrm{Z}=0$. Since the source used to probe the nonlinear material is a low power continuous wave laser, the origin of opticalnonlinearity of LiKP is attributed to the thermal variation of local refractive index in the medium. The response time of the material as recorded by an oscilloscope is found to be millisecond regime, which is to be expected in the case of such thermal nonlinearity. Nonlinear absorption property of the D- $\pi$-A type $\pi$-electron system can be related closely to the $\pi$-electron conjugate degree and delocalization capacity of the molecule. The three dimensional X-ray crystal structure solution of LiKP crystal showed that the torsional angles connecting the donor and acceptor atoms seem to have conjugated chains with coplanar planes. These may be some of the features that are favorable to nonlinear optical absorption, particularly to saturated absorption. Nonlinear refractive index $\left(n_{2}\right)$ of the LiNaP has been calculated as $6.6612 \times$ $10^{-11} \mathrm{~cm}^{2} / \mathrm{W}$ and nonlinear absorption coefficient was found to be $\beta \sim 9.1115 \times 10^{-3} \mathrm{~cm}^{2} / \mathrm{W}$.

\section{Conclusion}

Lithium Sodium Acid phthalate single crystal has been synthesized by slow evaporation method and the bulk crystals of dimension $9 \times 4 \times 2 \mathrm{~mm}^{3}$ have slow been grown from slow-cooling technique. The crystal structure of the newly synthesized compound was solved using single crystal X-ray diffraction analysis. The morphology of the grown crystal shows that the prominent plane $\left(\begin{array}{lll}0 & 0 & 1\end{array}\right)$ found to be the optically transparent one and is quite suitable for third order nonlinear optical ap- 
plications. The presence of various functional groups has been elucidated through FTIR analysis. The electronic transition spectrum showed the good transparency of the crystal in the visible $\&$ IR region and the $\lambda_{\text {cutoff }}$ occurs at $-200 \mathrm{~nm}$. Simultaneous TG-DTA studies on the grown crystal reveals that the title compound is thermally stable up on $130^{\circ} \mathrm{C}$ and it is fully decomposes by $529^{\circ} \mathrm{C}$. The third order nonlinear measurement using Z-scan techniques reveal the negative nonlinear (self defocusing) property of the sample is due to thermal effect. The nonlinear refractive and nonlinear absorption coefficient of the LiNaP crystal at $632.8 \mathrm{~nm}$ have been found to be $\mathrm{n}_{2}=6.6612 \times 10^{-11} \mathrm{~cm}^{2} / \mathrm{W}$ and $\beta \sim 9.1115 \times 10^{-3} \mathrm{~cm}^{2} / \mathrm{W}$ respectively.

\section{Supplementary Data}

Full crystallographic data (cif file) relating to the crystal structure have been deposited with the Cambridge Crystallographic Data Centre as CCDC 844344. Copies of this information can be obtained free of charge from the Cambridge Crystallographic Data Centre, 12 Union Road, Cambridge CB2 1EZ, UK (Fax: +44 1223 336033; dposit@ccdc.cam.ac.uk; http://www.ccdc.cam.ac.uk).

\section{REFERENCES}

[1] A.Smith, "The Crystal Structures of a Series of Salts of Phthalic Acid. II. The Crystal Structure of Sodium Acid Phthalate Hemihydrate," Acta Crystallographica Section $B$, Vol. 51, 1975, pp. 2345-2347. doi:10.1107/S0567740875007546

[2] H. Kuppers, "Structure of Lithium Phthalate Hemitrihydrate," Acta Crystallographica Section C, Vol. 44, No. 12, 1988, pp. 2093-2095. doi:10.1107/S0108270188008935

[3] G. Adiwidjaja and H. Kuppers, "Lithium Hydrogen Phthalate-Methanol," Acta Crystallographica Section B, Vol. 34, 1978, pp. 2003-2005. doi: $10.1107 / \mathrm{S} 0567740878007190$

[4] H. Kuppers, "Lithium Hydrogen Phthalate Monohydrate," Acta Crystallographica Section B, Vol. 34, 1978, pp. 3763-3765. doi:10.1107/S0567740878012121

[5] J. S. Loring, M. Karlsson, W. R. Faweett and W. H. Casey, "Infrared Spectra of Phthalic Acid, the Hydrogen Phthalate Ion, and the Phthalate Ion in Aqueous Solution," Spectrochimica Acta Part A, Vol. 57, No. 8, 2001, pp. 1635-1642. doi:10.1016/S1386-1425(01)00391-2

[6] D. S. Chemla and J. Zyss, "Nonlinear Optical Properties of Organic Molecules and Crystals," Academic Press, New York, 1987.

[7] N. Kejalakshmy and K. Srinivasan, "Growth, Optical and Electro-Optical Characterisations of Potassium Hydrogen Phthalate Crystals Doped with $\mathrm{Fe}^{3+}$ and $\mathrm{Cr}^{3+}$ Ions," Opti- cal Materials. Vol. 27, No. 3, 2004, pp. 389-394. doi:10.1016/j.optmat.2004.09.005

[8] J. G. Qin, D. Y. Liu , C. Y. Dai, C. T. Chen, B. C. Wu, C. L. Yang and C. M. Zhan, "Influence of the Molecular Configuration on Second-Order Nonlinear Optical Properties of Coordination Compounds," Coordination Chemistry Reviews, Vol. 188, No. 1, 1999, pp. 23-34. doi:10.1016/S0010-8545(98)00182-9

[9] P. G. Barber and J. T. Petty, "Use of Moments of Momentum to Predict the Crystal Habit in Potassium Hydrogen Phthalate," Journal of Crystal Growth, Vol. 100, No. 1-2, 1990, pp. 185-188.

doi:10.1016/0022-0248(90)90621-Q

[10] B. Orel, D. Hadzi and F. Carassi, "Infrared and Raman Spectra of Potassium Hydrogen Phthalate," Spectrochimica Acta A: Molecular Spectroscopy, Vol. 31, No. 2, 1975, pp. 169-182. doi:10.1016/0584-8539(75)80228-5

[11] B. N. Mavrin, M. V. Koldaeva, R. M. Zakalyukin and T. N. Turskaya, "Raman Spectra of Potassium, Rubidium, and Thallium Hydrogen Phthalates," Optika i Spektroskopiya, Vol. 100, No. 6, 2006, pp. 862-868. doi:10.1134/S0030400X06060099

[12] N. Balamurugan, M. Lenin and P. Ramasamy, "Growth of Potassium Acid Phthalate Crystals by Sankaranarayanan-Ramasamy (SR) Method and Its Optical Characterization," Materials Letters, Vol. 61, No. 8-9, 2007, pp. 1896-1898. doi:10.1016/i.matlet.2006.07.184

[13] A. Senthil, P. Ramasamy and G. Bhagavannarayana, "Synthesis, Growth, Optical, Dielectric and Thermal Studies of Lithium Hydrogen Phthalate Dihydrate Crystals," Journal of Crystal Growth, Vol. 311, No. 9, 2009, pp. 2696-2701. doi:10.1016/i.jcrysgro.2009.02.036

[14] A. Senthil and P. Ramasamy, "Unidirectional Growth of $<001>$ Sodium Acid Phthalate Single Crystal by Sankaranarayanan-Ramasamy (SR) Method," Journal of Crystal Growth, Vol. 311, No. 23-24, 2009, pp. 4720-4724. doi:10.1016/j.jcrysgro.2009.09.014

[15] H. Retajczak, "Book of Abstracts," Krakow, 2000, p. 21.

[16] H. Kuppers, F. Takusagawa and T. F. Koetzle, "Neutron Diffraction Study of Lithium Hydrogen Phthalate Monohydrate: A Material with Two Very Short Intramolecular O - H H O Hydrogen Bonds," Journal of Chemical Physics, Vol. 82, No. 12, 1985, pp. 5636-5647. doi: $10.1063 / 1.448550$

[17] A. K. Karnal, A. Saxena, H. L. Bhat, V. K. Wadhawan and T. P. S. Nathan, "A Novel Seed-Isolation Technique during the Processing of Solutions," Journal of Crystal Growth, Vol. 289, No. 2, 2006, pp. 617-620. doi:10.1016/j.jcrysgro.2005.11.101

[18] W. Clegg and L. Russo, "Synthesis and Structures of Alkali Metal Complexes of Isophthalic Acid: The Interplay of Organic Supramolecular Interactions and Flexible Metal Coordination as Structure-Directing Factors," Crystal Growth \& Design, Vol. 9, No. 2, 2009, pp. 11581163. doi: $10.1021 / \mathrm{cg} 800991 \mathrm{t}$

[19] Bruker APEX2, SADABS, XPREP and SAINT-Plus. 
Bruker AXS Inc., Madison, 2004.

[20] L. J. Farrugia, "ORTEP-3 for Windows-A Version of ORTEP-III with a Graphical User Interface (GUI)," Journal of Applied Crystallography, Vol. 30, 1997, pp. 565-568. doi:10.1107/S0021889897003117

[21] G. M. Sheldrick, "SHELXL97," University of Gottingen, Gottingen, 1997.

[22] A. C. T. North, D. C. Phillips and F. S. Mathews, "A Semi-Empirical Method of Absorption Correction," Acta Crystallographica Section A, Vol. 24, No. 3, 1968, pp. 351-353. doi:10.1107/S0567739468000707

[23] J. L. Bredas, C. Adant, P. Tackx and A. Persoons, "Thirdorder Nonlinear Optical Response in Organic Materials: Theoretical and Experimental Aspects," Chemical Reviews, Vol. 94, No. 1, 1994, pp. 243-278. doi:10.1021/cr00025a008

[24] M. Sheik-Bahae, A. A. Said, T. H. Wei, D. J. Hagan and
E. W. Van Stryland, "Sensitive Measurement of Optical Nonlinearities Using a Single Beam," Journal of Quantum Electronics, Vol. 26, No. 4, 1990, pp. 760-769. doi: $10.1109 / 3.53394$

[25] M. Sheik-Bahae, A. A. Said and E. W. VanStryland, "High-Sensitivity, Single-Beam $\mathrm{n}^{2}$ Measurements," $O p$ tics Letters, Vol. 14, No. 17, 1989, pp. 955-957. doi:10.1364/OL.14.000955

[26] E. W. Vanstryland and M. Sheik-Bahae, "Characterisation Techniques and Tabulation for Organic Nonlinear Materials," In: M. G. Kuzyk and C. W. Dirk, Eds., Marcel Dekker Inc., New York, 1998, pp. 655-692.

[27] A. A. Said, M. Sheik-Bahae, T. H. Wei, D.J. Hagan, J. Wang, J. Young and V. Stryland, "Determination of Bound Electronic and Free-Carrier Nonlinearities in ZnSe, GaAs, CdTe and ZnTe," Journal of the Optical Society of America B, Vol. 9, No. 3, 1992, pp. 405-414. doi:10.1364/JOSAB.9.000405 